\title{
Isolation and growth of a cytopathic agent from multiple sclerosis brain tissue
}

\author{
Anthony R White, Nichole S Dutton, and Robert D Cook \\ Veterinary and Biomedical Sciences, Murdoch University, Murdoch, Western Australia
}

\begin{abstract}
Although many studies support a role for viruses in multiple sclerosis (MS) etiopathology, no specific agent has been consistently associated with significant numbers of MS patients without concomitant detection in non-MS controls. Previous studies have shown the presence of viral-like structures in MS plaques, although the specificity of these structures for MS has been questioned. The present study describes the use of polyclonal antisera against feline and human brain-derived cytopathic agents and immunoaffinity chromatography to purify and partially characterize possible virus-like structures from MS brain tissue. Chromatography eluates from 4 MS brains contained pleomorphic particles up to $350 \mathrm{~nm}$ in diameter and tubular/filamentous-like structures approximately $10-18 \mathrm{~nm}$ in thickness. Inoculation of primary rat glial cell cultures with chromatography eluates from MS brain tissue resulted in a reproducible pattern of cytopathic effects in the form of multinucleation in cells identified immunocytochemically as oligodendrocytes. Antisera raised against the feline and MS-derived cytopathic agents were used to successfully immunolabel infected oligodendrocyte-like cells and syncytia and to detect a $66,000 \mathrm{M}_{\mathrm{r}}$ protein on Western blots of inoculated cultures or concentrated MS brain eluates. Similar structures, cytopathic effects (CPE) and protein expression were not observed in eluates from 5 control brains or in cultures inoculated with control brain eluates. These studies demonstrate that cytopathic, virus-like structures can be isolated from MS brain tissue using antisera raised against a cytopathic agent rescued from demyelinating brain lesions in cats. The identity of this agent and its possible role in MS aetio-pathology remains unknown. Journal of NeuroVirology (2002) 8, 111-121.
\end{abstract}

Keywords: oligodendrocyte; virus; cytopathic effects; cell culture; CNPase

\section{Introduction}

There is considerable epidemiological evidence that multiple sclerosis may have a viral etiology and there have been many reports on the presence or

Address correspondence to Anthony R White, CNS Infection and Immunity Group, Department of Neurogenetics, Imperial College School of Medicine (St Mary's campus), Norfolk Place, London, W2 1PG, England. E-mail: tony.white@ic.ac.uk

The constructive editorial comments of Dr G Wilcox and the expert technical assistance of Dr D Berryman and Mr P Fallon are greatly appreciated as is the donation of the anti-CNPase antisera by Dr TJ Sprinkle. Mr G Griffiths and Mr B Kreunen assisted in the preparation of the micrographs. The research was supported by a grant from the School of Veterinary Studies, Murdoch University. ARW was a recipient of an Australian Postgraduate Research Award.

Received 3 May 2001; revised 26 June 2001; accepted 24 October 2001. absence of viral agents in MS-associated tissues (Prineas, 1972; Narang and Field, 1973; Raine 1975; ter Meulen and Stephenson, 1983; Johnson, 1985; Ehrlich et al, 1991; Allen and Brankin, 1993). Although viral isolations have been performed from MS tissues, these have not been reproducible and/or similar agents have been isolated from non-MS tissues. Paramyxoviruses or closely related agents have been suggested as possible candidates if MS is of a viral etiology. This is based on elevated titres of antibodies to measles virus (MV) in sera and cerebrospinal fluid (CSF) of MS patients (Norrby, 1978), the presence of paramyxovirus-like inclusions in MS tissues (Narang and Field, 1973; Tanaka et al, 1974, 1975; Pathak and Webb, 1976; Prasad et al, 1977), and that known morbilliviruses are associated with demyelination in the central nervous system (CNS) (Muller et al, 1995). However, attempts to reproducibly demonstrate MV, related paramyxoviruses, or viral nucleic acids in MS 
brain (Field et al, 1972) or other tissues (Kirk and Hutchinson, 1978; Fraser et al, 1982; Goswami et al, 1984; Brankin et al, 1996) have been unsuccessful.

The highly sensitive and specific technique of polymerase chain reaction (PCR) has also been applied to MS tissues in an attempt to detect viral genomes (Reddy et al, 1989; Buckle et al, 1992; Godec et al, 1992; Svenningsson, 1992; Brankin et al, 1996); however, no consistent and specific presence of viral nucleic acids has been detected. More recently, studies have centered on a retrovirus repeatedly isolated from MS patients (Perron et al, 1997; KomurianPradel et al, 1999) and human herpes virus-6 (HHV-6) protein and DNA expression in MS patients (Ablashi et al, 1998; Albright et al, 1998; Bergstrom, 1999; Campadelli-Fiume et al, 1999; Enbom et al, 1999). These and other studies have added considerable emphasis to a viral trigger for MS (Kurtzke, 1993; Cook et al, 1995; Souberbielle et al, 1995; Monteyne et al, 1998; Berti and Jacobson, 1999).

Ultrastructural analysis of feline brain material revealed plaques of CNS demyelination, morphologically similar to lesions observed in MS brains, in approximately $7 \%$ of the domestic cat population (Cook, 1979; Cook and Wilcox, 1985). Glial cells in the feline brain lesions contained inclusions bearing 16-18 nm diameter tubules that resembled paramyxovirus nucleocapsids. Cocultivation techniques were applied to feline white matter explant cultures and this resulted in the recovery of 3 cell-lines containing mildly cytopathogenic viruses (Wilcox et al, 1984). The cell-lines, MV631, CCA147, and MV907, expressed cytopathic effects in the form of syncytia and inclusion bodies and EM studies revealed the presence of 16-18-nm diameter paramyxoviral-like tubules within cytoplasmic inclusions. These tubules were cross-reactive with antisera to morbilliviruses and inoculation of the feline viruses into mice induced demyelination in some strains (Flower, 1988).

Immunocytochemical analysis of the cell-lines and the feline and MS brain lesions using antisera to the feline viral isolates revealed an antigenic relationship between the paramyxoviral-like tubules in cultured cell-inclusions and similar tubules in feline and MS lesions (CLPs) (Cook et al, 1986). Paramyxovirion-like particles, antigenically related to the nucleocapsid-like structures, were also detected in MS brain tissue and could be purified by immunoaffinity chromatography using antisera to the feline virus (Cook, February 1994, personal communication). Inoculation of the chromatography eluate into CV1 cells resulted in expression of cytopathic effects similar to those identified in feline virusinfected cells. These studies suggested a possible link between the feline and MS lesions and associated viral-like particles.

These data suggested that purification of the putative virus-like structures (tubular/filamentous and circular particles) may be possible using immunoaffinity chromatography. This would allow further examination of the nature of these structures and their relationship to demyelination in MS and feline brain. We report here on the immunoaffinity chromatographic isolation of pleomorphic particles and tubular/filamentous structures from MS (but not non-MS) brain tissue initially using antisera to the cytopathic feline-derived agent, MV631, and subsequently to a cytopathic MS brain-derived agent (CV1/MS) (Cook et al, 1986). The chromatography eluates from MS brain tissue induced a cytopathic effect in cells identified as oligodendrocytes when added to primary glial cell cultures. These data suggest that an oligodendrocytotrophic agent may exist in MS plaques and could play a role in MS etiology.

\section{Results}

\section{Electron microscopic analysis of immunoaffinity chromatography eluates}

Immunoaffinity chromatography was applied to MS brain tissue using anti-MV631 (feline brain-derived isolate) (Cook et al, 1986). Subsequently, antisera to Vero cell cultures inoculated with an MS brainderived agent, CV1/MS, was used to purify particles from additional MS brain samples. The antisera has previously been used to immunostain possible virus-like structures distinct from myelin degradation products in brain tissue of cats and MS patients (Wilcox et al, 1984; Cook et al, 1986). Electron microscopic examination of concentrated (ultracentrifugated) affinity chromatography eluates from MS brain obtained using either anti-MV631 (or anti-CV1/MS) antisera revealed the presence of pleomorphic (generally circular) structures ranging from about 100 to $350 \mathrm{~nm}$ in diameter and tubular/filamentous structures approximately 10 to $18 \mathrm{~nm}$ in diameter (Figure 1A-D). These structures were observed by EM in all eluates from four MS brain samples but not in eluates from five control brains. Some portions of the filamentous structures revealed possible cross-striations but this was not a consistent finding (Figure 1A). The structures did not consistently reveal any known virus-like morphology. However, they did resemble particles labelled with anti-MV631 or anti-CV1/MS in feline and MS demyelinating brain lesions (Cook and Wilcox, 1985; Cook et al, 1986). This suggests that the structures are not likely to be myelin degradation products (MDP) as MDPs were unlabelled with the anti-MV631 or anti-CV1/MS antibodies in MS lesions (Cook et al, 1986). In addition, similar structures were not isolated from, or detected in, control brain tissue. Tubular/filamentous and circular structures were also isolated from nonplaque MS brain tissue (data not shown). These data demonstrate that it is possible to use immunoaffinity chromatography to isolate pleomorphic and tubular/filamentous structures specifically from MS but not control brain tissue. The possible viral nature of these structures remains to be determined. 

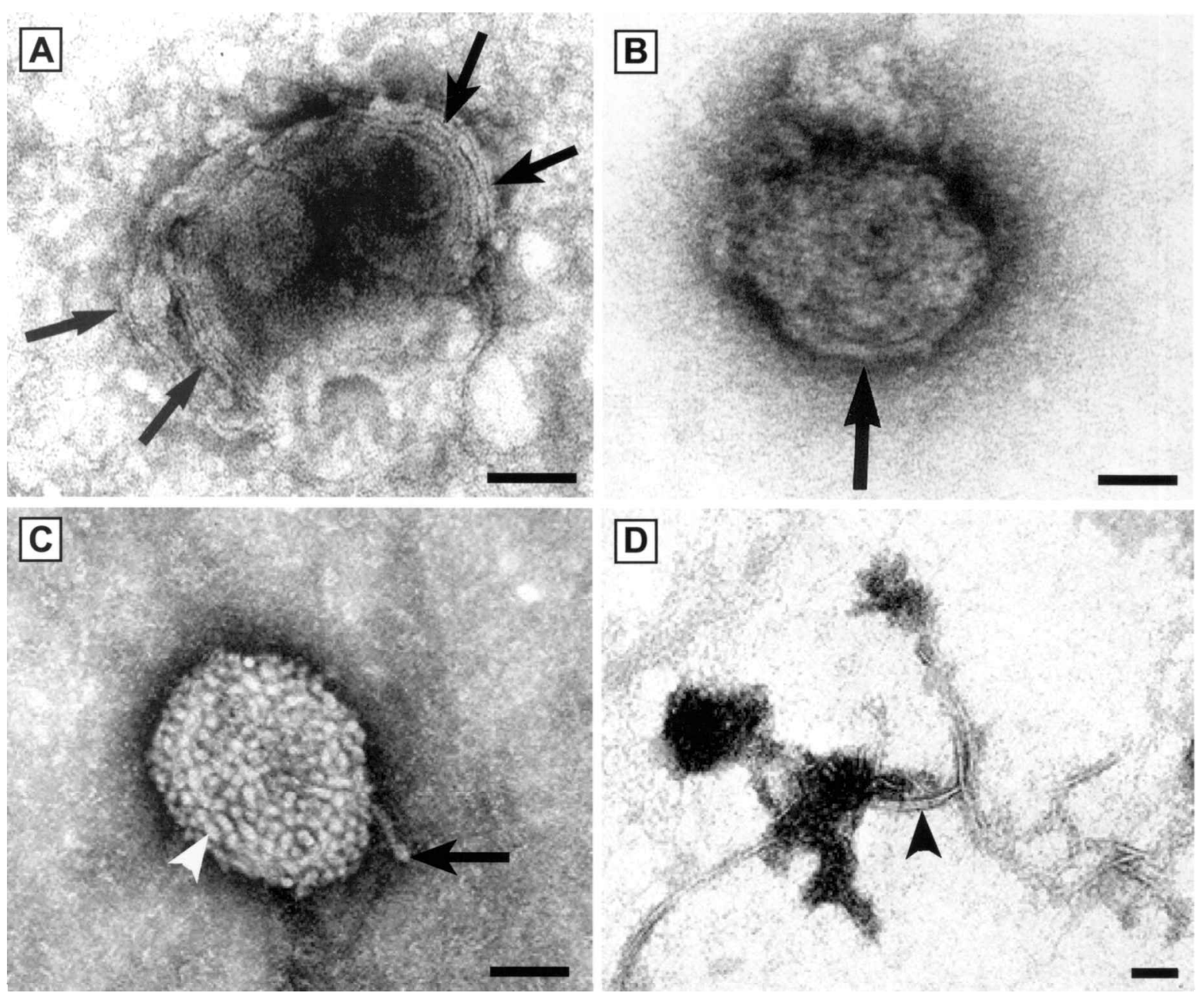

Figure 1 Electron microscopic analysis of MS brain affinity chromatography eluates. MS brain tissue was passed over Affi-gel columns adsorbed with anti-MV631 as described in Methods and Materials. Each figure is a representative micrograph from a separate MS brain elution. (A) and (B) MS-derived pleomorphic particles revealing 10-13 nm diameter filamentous structures (arrows). Possible crossstriations are visible on the filaments in Figure A. (C) MS-derived pleomorphic particle revealing 10-18 nm diameter structures in cross-section (arrowhead) and longitudinal view (arrow). (D) MS-derived 10-18 nm diameter filamentous structures in longitudinal view (arrowhead). No specific structures were identified in control brain eluates. All particles were negatively stained with $3 \%$ PTA. Scale bars $=$ $100 \mathrm{~nm}(\mathbf{A}, \mathbf{C}$, and $\mathbf{D})$ and $50 \mathrm{~nm}(\mathbf{B})$.

\section{Inoculation of primary rat glial cell cultures}

To determine if the MS brain eluates contained demonstrable viral-like properties, primary rat glial cell cultures were inoculated with either MS or control brain eluates. The primary glial cultures consisted of a bed layer of astrocytes over which grew oligodendrocytes as described by McCarthy and DeVellis (1980). The latter cells were initially identified by morphology according to Kuhlmann-Krieg et al (1988) and this was confirmed by positive immunostaining for the oligodendrocyte-specific markers, CNPase and GalC (data not shown). Chromatography eluates were applied to cultures at 4-7 days in vitro as described in Methods and Materials and cultures were fixed for immunocytochemistry after 6-14 days postinfection (p.i.).

Between 6 and 9 days p.i., there was clear evidence of cytopathic effects (CPE) in the form of multinucleated giant cells (syncytia) in MS eluateinoculated cultures (Figure 2). The level of CPE increased to reach a peak at about 14 days p.i. After this, the CPE was lost in parallel with the normal death and detachment of oligodendrocyte-like cells (data not shown). CPE was observed in cultures infected with four separate MS brain eluates. No cultures inoculated with three non-MS brain eluates or uninoculated cultures revealed CPE at any stage.

\section{Oligodendrocyte-like cells and syncytia revealed immunolabelling with anti-MV631 and anti-CV1/MS in cultures inoculated with MS brain eluates} Immunocytochemical analysis of inoculated cultures revealed clear immunostaining of syncytia with antisera to the oligodendrocyte marker, CNPase (Figure 2A) and GalC (data not shown). No staining 

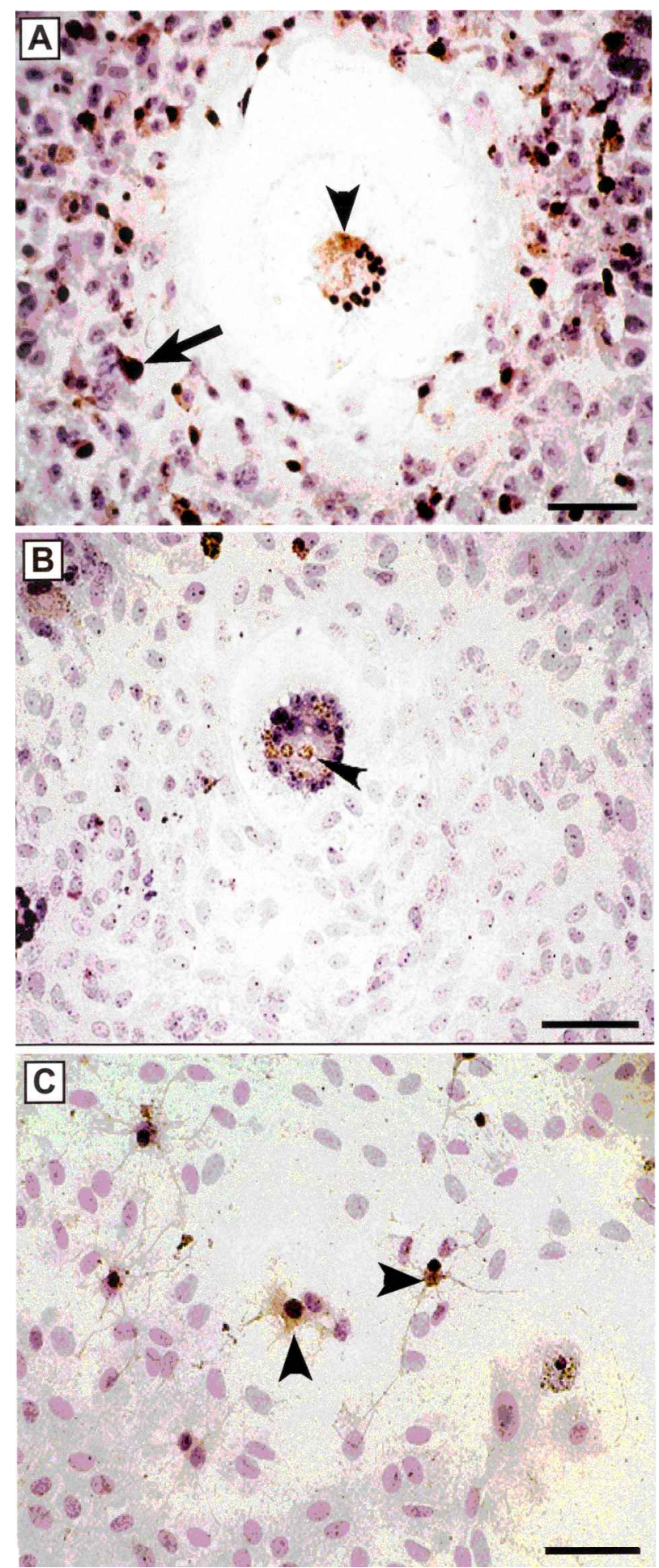

Figure 2 (A) Light micrograph of a multinucleated cell in a glial culture 9 days post inoculation (p.i.) with an MS brain eluate. CNPase-associated peroxidase stain can be seen within the cytoplasm of the multinucleated cell (arrowhead) as well as in surrounding oligodendrocytes (arrow). The astrocytic bedlayer has retracted to form a concentric void around the multinucleated cell. (B) Light micrograph of a multinucleated cell in a glial culture 14 days p.i. with an MS brain eluate. A positive staining reaction with immunoperoxidase labelled anti-CV1/MS shows possible inclusion bodies (arrowhead) within the cytoplasm of the was seen in cultures incubated with HRP-labelled secondary antibody alone. Additionally, immunolabelling with anti-MV631 or anti-CV1/MS resulted in specific staining of syncytia (Figure 2B) and cells with the morphology of oligodendrocyte s (Figure 2C). Approximately $69 \%$ of oligodendrocyte-like cells revealed immunocytochemical stain for CV1/MS antigen. No immunostaining of the underlying astrocytic bedlayer was observed. Furthermore, no labelling of any cell-type with antisera to MV631 or CV1/MS was observed in any culture inoculated with non-MS brain eluates or in uninoculated cultures. Immunocytochemically labelled cells and CPE were observed in cultures inoculated with four different MS brain eluates but not with three non-MS eluates. Anti-MV631 and anti-CV1/MS-detectable antigen was passaged to fresh uninoculated oligodendrocyte cultures using freeze-thawed, homogenized CPE-positive cultures or concentrated media taken from cultures showing obvious CPE. Addition of freeze-thawed cultures or media to fresh primary glial cultures resulted in the appearance of oligodendrocyte-lik e cells immunopositive for MV631 and CV1/MS between 6 and 14 days p.i. MV631-immunopositive cells were identified after two passages of freeze-thawed cultures. Further passages were not attempted. Significantly, syncytia were not observed in these cultures suggesting that the agent may be present as a persistent non-permissive infection in some oligodendrocytelike cells. These data clearly indicate that a cytopathic agent antigenically related to structures identified in and purified from feline and MS brain (but not control brain) tissue can be grown in cells morphologically and immunocytochemically identified as oligodendrocytes.

Electron microscopic analysis of concentrated medium from cultures inoculated with MS-brain eluates revealed the presence of pleomorphic particles resembling those seen in the MS brain eluates (Figure 3A). The particles contained circular and filamentous profiles approximately 10 to $18 \mathrm{~nm}$ in diameter. Ultrastructural analysis performed on sections of inoculated glial cell cultures resulted in the detection of cytoplasmic inclusions bearing circular or filamentous-like structures in oligodendrocyte-like cells (cells containing microtubules but lacking intermediate filaments) (Figure 3B and C). Some cells containing cytoplasmic inclusions were positively labelled with antisera to CNPase (data not shown). However, this was not a consistent finding and may have a been due to minimal penetration of CNPase antisera into the cytoplasm as strong staining was often seen adjacent to the plasma membrane. The filamentous structures were clearly seen in longitudinal section and cross-section in oligodendrocyte-like cells

multinucleated cell. (C) Immunostaining of oligodendrocyte-like cells with CV1/MS antisera 7 days p.i. (arrowheads). Underlying bedlayer of astrocytes does not reveal immunostain. Cultures were counterstained with haematoxylin. Scale bars $=25 \mu \mathrm{m}$. 

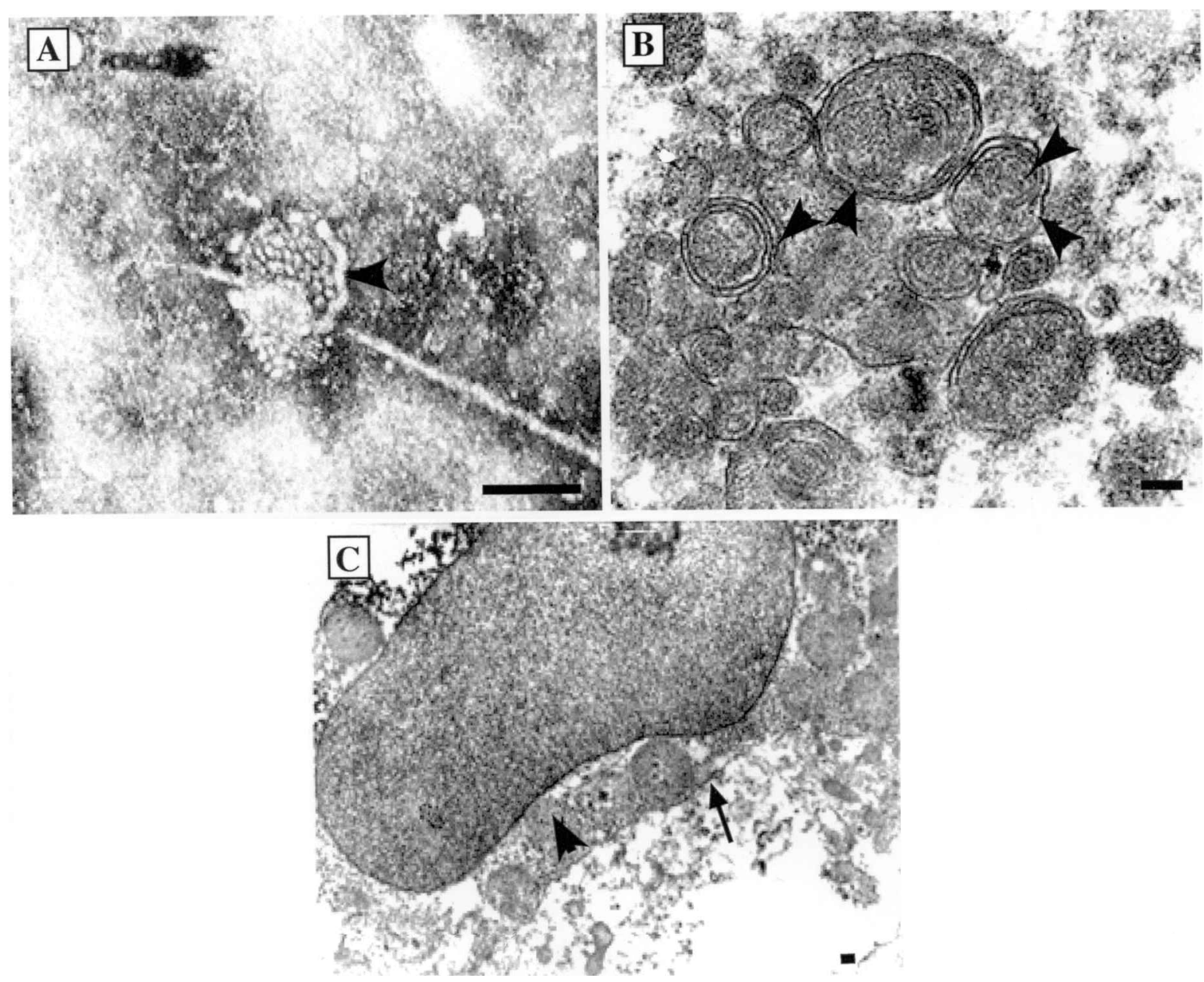

Figure 3 (A) Electron micrograph of a pleomorphic particle purified from concentrated media of MS brain eluate-infecte d glial cultures. The 10-18 nm diameter structures can be seen in cross section and longitudinal section (arrowhead). Similar structures were not identified in control media. Note the similarity to the particle shown in Figure 1C purified from MS brain tissue. (B) Electron micrograph showing 10-18 nm tubular or filamentous structures within the cytoplasm of an oligodendrocyte from a culture inoculated with an MS brain eluate. The cytoplasm of many oligodendrocyte-like cells (cells containing microtubules but lacking intermediate filaments) contained large numbers of circular inclusions consisting of coiled tubules or filaments (arrowheads). Similar structures were not identified in control cells. (C) Electron micrograph showing cytoplasmic inclusions (arrowhead) within the cytoplasm of an oligodendrocyte-like cell from a culture inoculated with an MS brain eluate. The plasma membrane is indicated (arrow). Similar structures were not identified in control cells. Scale bars $=100 \mathrm{~nm}$.

and were approximately 10 to $18 \mathrm{~nm}$ in diameter. The structures resembled those observed in the MS brain eluates and in MS brain tissue plaques (Cook et al, 1986) but were not identified in cells inoculated with control brain eluates or in uninoculated cultures. Although possible viral-like budding was observed in some cells close to the inclusions, the true nature of the structures could not be determined as we were unable to consistently label the structures with antisera to CV1/MS (data not shown).

\section{SDS-PAGE and immunoblot analysis}

SDS-PAGE and silver stain analysis of affinity chromatography eluates revealed the presence of a 66,000 dalton (66 $\mathrm{kDa}$ ) protein band in MS but not control brain eluates (Figure 4A). Additional protein bands were occasionally but not consistently observed. Immunoblotting of chromatography eluates with anti-
MV631 labelled a band at $66 \mathrm{kDa}$ in all MS isolates examined (four) but not in non-MS eluates (three). Representative samples are shown in Figure 4B. The protein band was detected with antisera to MV631 (Figure 4B) and anti-CV1/MS (data not shown). Adsorption of the antisera using MS eluates could not be performed due to the small amount of antigen obtained in the elutions. Analysis of pooled MS eluateinoculated glial cell lysates also revealed the presence of a 66-kDa protein after immunoblotting with anti-MV631 (Figure 4C). This band was not present in uninoculated cultures or in cultures inoculated with control brain eluates. No detection of proteins was achieved with secondary antisera alone and no other proteins specific to the MS- or feline agent-infected cultures were consistently detected by immunoblotting. This may have been due to a lack of sensitivity using polyclonal antisera. 
A
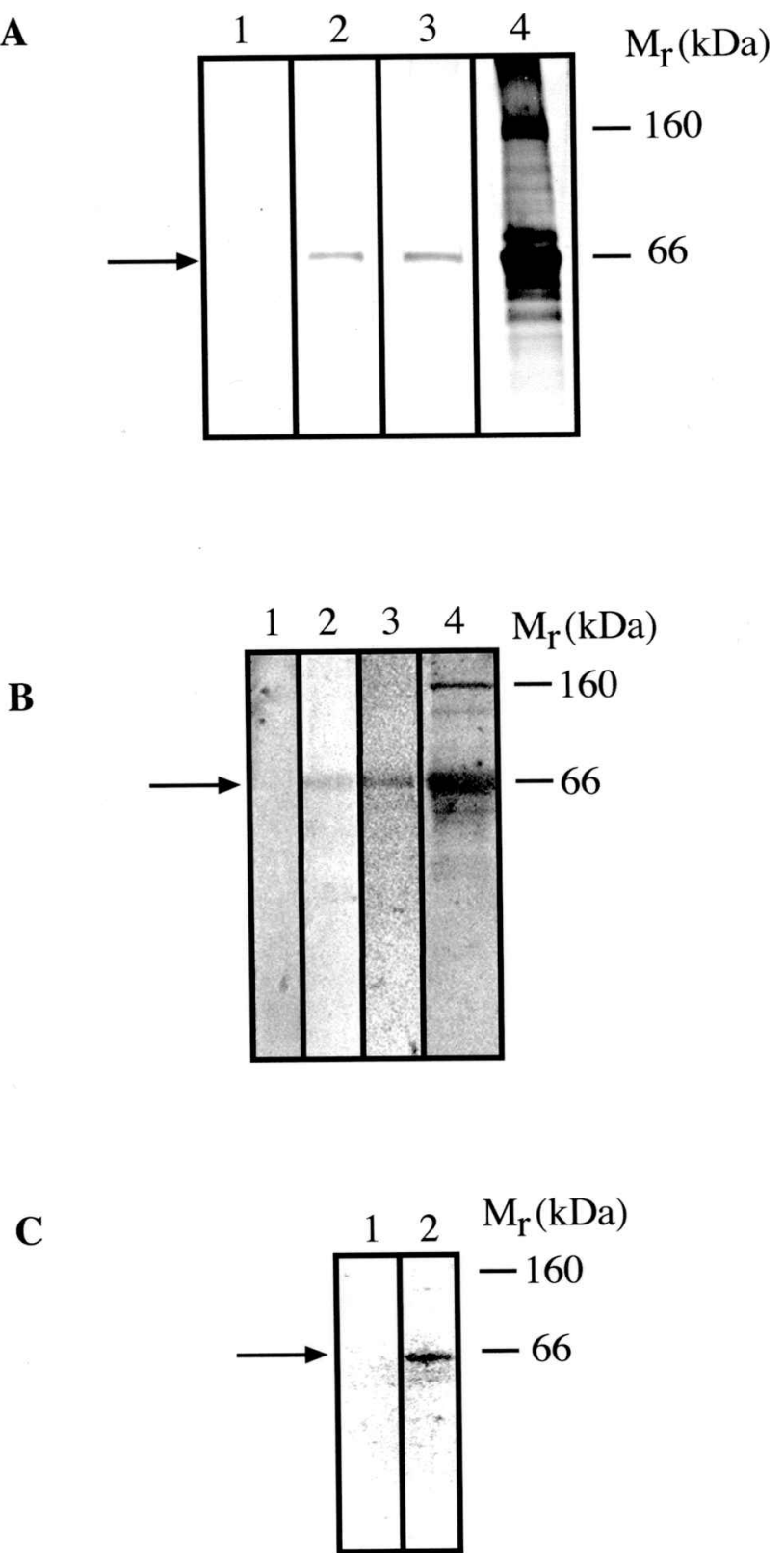

Figure 4 SDS-PAGE and Western blot analysis of MS brain eluates and inoculated glial cultures. (A) Proteins in MS and control brain eluates were separated by SDS-PAGE and visualized by silver staining. Lane 1: control brain eluate; lanes 2-4: MS brain eluates. A protein with a molecular weight of 66,000 daltons $(66 \mathrm{kDa})$ (arrow) is clearly shown in the three MS eluates. Additional proteins were identified only in one MS eluate. No protein bands are evident in the control brain eluate. (B) Proteins in MS and control brain eluates were separated by SDS-PAGE, transferred to nitrocellulose, and immunoblotted with anti-MV631. Lane 1: control brain eluate; lanes 2-4: MS brain eluates. A $66-\mathrm{kDa}$ protein band (arrow) was identified in all MS brain eluates but not in control brain eluates. A $160-\mathrm{kDa}$ band was identified only in one MS eluate (lane 1). (C) Control or MS brain-inoculated glial cultures were pooled and proteins extracted. Samples were separated on SDS-PAGE gels, transferred to nitrocellulose, and immunoblotted with anti-MV631. Lane 1: control cultures; lane 2: MS brain inoculated cultures. A 66-kDa protein band (arrow) was detected in the MS brain-inoculated glial cultures but not control cultures.
Interestingly, immunoblotting with human sera as the primary antibody resulted in detection of the 66-kDa protein band using both MS and non-MS control sera obtained from the Red Cross Blood Association (seven of each) (data not shown). This lack of specificity may be due to cross-reaction of viral antibodies to the $66-\mathrm{kDa}$ protein in the general population. This is supported by our observation that polyclonal antisera to measles virus also detects the 66-kDa protein on Western blots. Alternatively, the $66-\mathrm{kDa}$ protein may represent a ubiquitous antigen that is associated with disease only in a small portion of the population. However, our results do show that a $66-\mathrm{kDa}$ protein is present in MS but not control brain eluates purified with antisera to the feline cytopathic agent and that the protein cross-reacts with antisera to another MS-derived cytopathic agent (CV1/MS). The findings also show that a $66-\mathrm{kDa}$ protein is synthesized de novo in glial cell cultures inoculated with MS- or feline-derived cytopathic agents and that the protein is recognized by antisera in both MS patients and the general population.

\section{Discussion}

The results of this study show that structures specific to MS brain tissue can be repeatedly isolated with immunoaffinity chromatography and antisera to cytopathic agents derived from feline and MS brain tissue. These structures induce consistent cytopathic effects in cells identified immunocytochemically as oligodendrocytes in culture whereas control eluates have no effect. Moreover, the MS brain eluates and infected glial cells reveal the presence of detectable protein antigen not found in control samples. The nature of the cytopathic agent is unknown but, significantly, shows oligodendrocytotrophis $\mathrm{m}$ in vitro. As oligodendrocytes are the prime neuroglial cell-type involved in MS pathology, the possible replication of this agent in oligodendrocytes with the concommitant induction of cytopathology suggests that the agent could be related to the pathology of MS. To confirm this, however, similar isolation and cell culture inoculation studies will need to be performed on a number of non-MS neurological and neuroinflammatory control brain samples to determined the specificity of the cytopathic agent to MS patients.

The use of affinity chromatography columns as a method of attempted virus isolation does not appear to have previously been applied to MS tissues. The advantages over standard cocultivation viral rescue techniques are that it does not require the use of living MS brain tissue, can be used to isolate nonreplicative structures, and is less complicated by the presence of unrelated viral flora present in brain tissue. There is, however, the problem of purifying a range of cross-reactive agents, particularly when using polyclonal antisera. A significant disadvantage to the procedure is that harsh conditions (low $\mathrm{pH}$ 
$\mathrm{NaCl}$ or citrate buffer) are used to elute the antigen from chromatography columns. The low $\mathrm{pH}$ buffer is likely to destroy the infectivity of labile virus. In fact, in the present study it was surprising that MS chromatography eluates prepared in this manner had the ability to consistently induce cytopathology and $d e$ novo protein replication in cultures despite the harsh isolation procedure. The presence of de novo replication was confirmed by passaging the agent to fresh glial cell cultures. We hypothesize that the cytopathic agent may have been obtained in the first fractions of column eluate in which changes to the $\mathrm{pH}$ and salt levels would be minimal. Subsequent fractions may have contained non-infectious proteins. We did not, however, examine individual fractions for infectivity and this raises the possibility that the cytopathic agent may not be directly related to the structures purified from the MS plaques.

Previous agents have been rescued from MS brain and peripheral tissues by traditional coculture techniques; however, none of these agents have yet been consistently isolated or linked to the etiology of MS (Johnson, 1985; Allen and Brankin, 1993; Souberbielle et al, 1995). A retrovirus (LM7) has recently been isolated from a number of MS patients and may play a role in MS (Perron et al, 1997; Komurian-Pradel et al, 1999), however, this agent is still being characterize $d$ and has not yet been purified from MS plaques. Additionally, HHV-6 has been implicated in MS etiology (Ablashi et al, 1998; Albright et al, 1998; Bergstrom, 1999; Campadelli-Fiume et al, 1999; Enbom et al, 1999) and, significantly, can induce cytopathic effects in oligodendrocyte s (Albright et al, 1998). It remains to be determined whether HHV-6 has a causal role in MS pathology.

In the present study, MS-specific pleomorphic structures and proteins were purified from four confirmed cases of MS but not from five non-MS brains using antisera raised against feline (MV631) and an MS brain-purified cytopathic agent (CV1/MS) (Wilcox et al, 1984; Cook et al, 1986). Following inoculation into glial cell cultures, the MS brain but not control eluates induced syncytia and de novo synthesis of protein antigenically related to the purified protein. These data indicate that a specific oligodendrocytopathic agent related to a feline-derived cytopathic agent (Wilcox et al, 1984; Cook et al, 1986) can be repeatedly isolated from MS brain tissue but is not obtained from non-MS tissue. Our studies also revealed that the MS-specific proteins can sometimes be purified from nonplaque-associated white matter in MS brain tissue (data not shown). This suggests that the agent/protein is not only associated with lesionous tissue and that the lack of purification from non-MS brain tissue is not simply due to a lack of plaques per se. Our studies at present have not included the attempted isolation of the agent from plaque tissue of other neurological disorders. It is possible that the agent may be sequestered at the lesionous site due to inflammatory cell infiltration.
Although isolation of the agent from nonplaque MS tissue does not support this, it is possible that lymphocytic infiltration has occurred in the non-plaque tissue. The present study involved a preliminary screening of MS and control brain tissue for purification of a cytopathic, viral-like agent antigenically related to a feline-derived agent. Further analyses will be required to determine if the agent and particular ultrastructural variants are related to lymphocytic infiltration or clinical course of the disease.

The EM morphology of the particles purified from MS brain tissue revealed the presence of pleomorphic and tubular/filamentous structures suggesting a possible viral nature. This was supported by the cytopathic effects upon inoculation of glial cell cultures. In addition, we have observed demyelinating lesions in some mice inoculated with the felinederived cytopathic agent (Flower, 1988) and have detected putative RNA sequences with high homology to the morbillivirus nucleocapsid gene in MS brain eluates using PCR and degenerate primers (unpublished observations). However, these findings are preliminary and require further analysis, particularly of additional viral gene sequences, before conclusive identification of the cytopathic agent can be made. In the present study, tubular/filamentous structures were identified longitudinally and in cross-section and showed some resemblance to viral-like nucleocapsid structures. However, an accurate viral classification of the particles could not be made due to the heterogeneity of the structures isolated (i.e., 1013-nm filaments with cross-striation s in some eluates compared to $16-18-\mathrm{nm}$ plain filaments in others). The reason for this is unknown but could represent normal variation between isolates or artefactual differences due to variation s in the elution conditions.

Only one protein band was consistently detected by SDS-PAGE and Western blotting. Although this band (66 $\mathrm{kDa}$ ) is similar in $\mathrm{M}_{\mathrm{r}}$ to the nucleocapsid protein (NP) of some paramyxoviruses (Diallo et al, 1987), the lack of other detectable proteins and the lack of particles with consistent paramyxovirus-like morphology in the eluates precludes conclusive identification. Monoclonal antisera to a number of viral proteins in conjunction with PCR may help to identify the agent.

It is interesting to note that tubular/filamentous structures similar to those described here have been reported to occur in MS brain plaques. These structures have been termed curved-linear profiles (Prineas, 1975), tubulo-reticular bodies (Mirra and Takei, 1976), rod-shaped tubular structures (Kirk and Hutchinson, 1978), and Wiebel-Palad e bodies (Allen, 1981). However, similar structures have also been reported in other neurological illnesses (Prineas, 1975; Hayano et al, 1976; Hauw and Esourolle, 1977), indicating a lack of specificity to MS. Structures similar to the pleomorphic particles described here have also been previously reported in MS brain tissue (Pathak and Webb, 1976), but there is still debate on a 
viral origin of these structures (Kirk and Hutchinson, 1978; Kirk and Zhou, 1996). Although these structures are generally considered to be myelin degradation products by morphology alone (Rodriguez and Scheithauer, 1994), Cook et al (1986) demonstrated that myelin products were differentially labelled (with GalC) compared to the pleomorphic and tubular structures labelled with antisera to MV631 and CV1/MS. Our findings do suggest that at least some of the structures isolated from MS plaques may have an infectiou s and cytopathic nature in vitro. The specificity of this agent to MS lesions, however, remains to be shown.

Perhaps the most important aspect of the current study is that the eluates obtained from MS brain tissue, but not those from non-MS tissue, were able to repeatedly induce a cytopathic infection in oligodendrocyte-like cells in vitro. As the oligodendrocyte is the myelinating cell-type in the CNS, and MS is characterized by lesions of demyelination, it is interesting to speculate that the replication of a cytopathic agent (as reported in this study) could be responsible for perturbations to oligodendroglial metabolism leading to demyelination. The majority of oligodendrocytes infected in our cultures did not die more rapidly than in controls but appeared to harbor a persistent infection, sometimes involving CPE. Moreover, when the agent was passaged to fresh glial cultures, there was no evidence of CPE, despite immunocytochemically detectable MV631- and CV1/MS-related antigens in the oligodendrocytes. These data suggest that the agent may be defective in some aspect of maturation and therefore form a nonpermissive, persistent infection similar to that reported for viruses such as SSPE isolates. Defective replication or maturation may also be responsible for the lack of consistently successful virus rescue attempts from MS brain tissue (Mitchell et al, 1978; ter Meulen et al, 1972).

Interestingly, no reports of using glial cell cultures or oligodendrogliom a cell-lines in an attempt to rescue virus from MS brain have been reported. In our hands, the agent does not replicate well in kidney cells commonly used for viral rescue. The growth is very slow compared to growth in oligodendrocytes (i.e., months versus days to get CPE and readily detectable antigen). The oligodendrocytotrophis $m$ of the agent described here may indicate that this celltype contains factors required for viral replication or maturation. One such factor may be CNPase activity. This protein/enzyme is present at high levels in oligodendrocytes and CNPase activity has been reported in nucleocapsids derived from RNA viruses such as Newcastle disease virus (Rosenbergova and Pristasova, 1991). It remains to be seen whether the agent described here also contains CNPase activity.

Conclusive identification of the cytopathic agent described here will depend upon PCR detection and/or sequencing of a putative genome. Although the findings presented here represent only a prelim- inary study of MS versus normal control tissue, they establish that a cytopathic agent can be consistently and specifically isolated from MS brain tissue and grown in oligodendrocytes in vitro. Full characterization and the role of the agent in MS aetiology remains to be determined.

\section{Methods and materials}

Affinity chromatography was performed on brain tissue from four cases of MS and five non-MS controls. Brain samples were kindly supplied by Drs B. Kakulas, Department of Neuropathology, Royal Perth Hospital, Perth, Western Australia; C. Bernard, Department of Neuroimmunology, La Trobe University, Melbourne, Victoria, Australia, and W. W. Tortellotte, Veterans Administration Medical Centre, Wadsworth, Los Angeles, California, USA. The brain samples were derived from autopsy material and confirmed as MS or non-MS (nonneurological illness) by routine clinical and histopathological assessment at the originating laboratory. Brain tissue was kept at $-70^{\circ} \mathrm{C}$ prior to affinity chromatographic studies for 1 to 7 years.

\section{Immunoaffinity chromatography}

Antisera Isolation of the feline brain-associated cytopathic agent (MV631) and antibody preparation to this agent has been reported elsewhere (Wilcox et al, 1984; Cook et al, 1986). Polyclonal rabbit antisera to an MS viral isolate (CV1/MS) was prepared in the same manner as the antisera to feline isolates. Homogenates of Crandell feline kidney cells (CRFK) or Vero cell cultures expressing cytopathic effects from MV631 or CV/1 agents were inoculated into rabbits with Freund's adjuvant for polyclonal antibody preparation. Protein purification from rabbit sera was carried out by ammonium sulfate precipitation at $\mathrm{pH} 7.5$, followed by dialysis against $10 \mathrm{mM}$ phosphate buffer ( $\mathrm{pH}$ 7.5). The IgG was further purified on an Affigel Protein-A (BioRad) affinity chromatography column, concentrated with polyethylene glycol (PEG), dialyzed again, and examined electrophoretically for purity. To remove nonspecific (noncytopathic agent) antibodies, IgGs were incubated overnight $(\mathrm{O} / \mathrm{N})$ at $4{ }^{\circ} \mathrm{C}$ with methanol-fixed CRFK cells (kindly donated by the Department of Agriculture, South Perth, Western Australia) and cat liver powder $(0.2 \mathrm{~g}$ per $1 \mathrm{~mL}$ sera). The liver powder was removed by centrifugation. The antisera was then filtered through a $0.45-\mu \mathrm{m}$ Millipore filter to remove remaining debris. For immunoblotting and immunocytochemistry, antisera were conjugated to horseradish peroxidase (HRP). Antisera to MV631 was initially used to isolate putative virus-like structures from MS brain tissue by affinity chromatography (unpublished data). These structures were inoculated into a kidney Vero cell-line (CV1/MS) and used to raise polyclonal antisera in rabbits (Cook et al, 1986). The antisera used in 
the present study are hence termed anti-MV631 (antifeline brain-derived agent) and anti-CV1/MS (antiMS brain-derived agent) (Cook et al, 1986).

Chromatography Affi-Gel 10 matrix (BioRad) was used to purify structures bound to anti-MV631 or anti-CV1/MS from MS brain tissue. The matrix was freshly prepared and constituted as per directions for each brain used. Purified IgG (less than $30 \mathrm{mg} / \mathrm{mL}$ ) (anti-MV631 or anti-CV1/MS) was applied to the gels overnight at $4^{\circ} \mathrm{C}$. Excess IgG was washed from the gel using binding buffer. Then $1 \mathrm{~g}$ to $2 \mathrm{~g}$ of brain tissue was excised from macroscopically defined MS plaques or from control (non-MS) brain tissue, was homogenized, and then sonicated in phosphate-buffered saline (PBS) containing 1\% Tween 20. The sample was mixed with the affinity column in batch or flow-through method followed by washing with bicarbonate buffer. The virus-like structures were eluted using citrate or $\mathrm{NaCl}$ buffer at various $\mathrm{pH}$ (starting with $\mathrm{pH} 6.0$ and sequentially lowering the $\mathrm{pH}$ to 3.0 ). The column fractions were added to $\mathrm{pH}$ neutral PBS and centrifuged at 69,000 $\times$ $\mathrm{g}$ for $3.5 \mathrm{~h}$. All experimental procedures were undertaken in the electron microscope laboratory that had not been used for other viral studies.

Electron microscopy of chromatography eluates Concentrated (ultracentrifugated ) affinity chromatography eluates were applied to Formvar-coated copper grids, stained with $3 \%$ phosphotungstic acid ( $\mathrm{pH}$ 7.5), air dried, and viewed with transmission electron microscopy.

Primary rat glial cell cultures Rat glial cell cultures were prepared from 1- to 2-day-old Wistar rat pups. Rat brain tissue was dissociated using the method of Labourdette et al (1979). The dissociated cells were seeded onto poly-L-lysine-coated (Sigma, Australia) 25- $\mathrm{cm}^{2}$ Costar (Edward Keller, Victoria, Australia) tissue culture flasks at a density equivalent to one brain per flask in $10 \mathrm{~mL}$ of Dulbecco's Modified Eagle's Medium (DMEM) (Gibco, Australia) with 10\% fetal calf serum (FCS) and allowed to grow to confluency ( 4 to 5 days in vitro). Upon confluency, the concentration of FCS (Gibco, Australia) was reduced to $5 \%$. The cultures were maintained at $37^{\circ} \mathrm{C}$ with $5 \%$ $\mathrm{CO}_{2}$. Media was changed twice weekly.

Inoculation of cultures Glial cell cultures were inoculated with affinity chromatograph y column eluates from MS and non-MS brains (as described above) 4-7 days after plating. Other cultures remained uninoculated. To inoculate, eluates were applied as $100 \mu \mathrm{L}$ in $2 \mathrm{~mL}$ of fresh culture media for $2 \mathrm{~h}$ at $37^{\circ} \mathrm{C}$, removed, original media returned, and cultures maintained as described previously. Passaging of viral material to fresh cultures was achieved by concentrating media from infected cultures (as for column eluates) and applying to cultures in the same manner as for column eluates. At least four separate flasks were inoculated with each eluate.

Immunocytochemistry Cultures, fixed with $2.5 \%$ glutaraldehyde and $4 \%$ paraformaldehyde in phos- phate buffer, were immunostained with a 1:50 dilution of polyclonal anti-MV631 or anti-CV1/MS (pre-adsorbed to proteins from uninfected celllines) (Cook et al, 1986). Separate cultures were also incubated with antisera to the oligodendrocyte markers $2^{\prime}, 3^{\prime}$-cyclic nucleotide $3^{\prime}$-phosphodiesterase (CNPase) (a generous gift from Dr. Terry J. Sprinkle, Veterans Administration Medical Centre, Wadsworth, Los Angeles, CA, USA) at 1:100 or galactocerebroside (GalC) (Serotec, Australia) at 1:200. These antibodies were used in either a direct technique in which the antibody had been conjugated with horseradish peroxidase (HRP) (1:200) (as described, Cook et al, 1986) or in an indirect technique in which the unlabelled primary antibody was applied to the cultures followed by an HRP-labelled goat anti-rabbit (GAR) antibody (Serotec, Australia). The procedures have been described previously (Cook et al, 1986). Cultures were counterstained with haematoxylin for light microscopy. Semiquantitation of labelled cells was performed by counting oligodendrocyte-lik e cells using light microscopy. At least 1000 cells were counted per flask (5 flasks) and recorded as either immunostained or unstained.

Electron microscopy Cultures fixed in $2.5 \%$ glutaraldehyde were prepared for electron microscopy as described by Wilcox et al (1984).

Immunoblotting Cultures were prepared for immunoblotting by scraping cells into $2 \mathrm{~mL}$ of cell lysis buffer (Tris-NaCl-EDTA) with $1 \%$ Triton X100, pH 7.4, homogenized in a Dounce homogenizer (20 strokes), followed by centrifugation at $3100 \times \mathrm{g}$ for $20 \mathrm{~min}$. Protein concentration in the supernatant was determined with a BioRad microprotein assay and normalized protein levels (25 $\mu \mathrm{g} / \mathrm{lane}$ ) were separated on $12 \%$ SDS-PAGE gels at $150 \mathrm{~V}$ for $2 \mathrm{~h}$ and transferred to nitrocellulose membranes (100 V for $1.5 \mathrm{~h})$. MS and control affinity chromatography eluates were prepared using identical volumes of elution buffer per gram of tissue and were concentrated in parallel with ultracentrifugation as before. As MS and control eluates contained different amounts of protein, equal volumes were applied to $12 \%$ SDS-PAGE gels. To ensure that the lack of protein detection in control eluates was not due to variations in the elution protocol, some control eluates were concentrated a further 10-fold compared to MS eluates using microconcentrators (Centricon). However, no protein was detected by silver stain or Western blot in any control sample. For Western blots, membranes were blocked overnight $\left(4^{\circ} \mathrm{C}\right)$ in $3 \%$ BSA and immunoblotted with anti-MV631 or anti-CV1/MS at 1:100 in Tris-buffered saline (TBS), pH 7.4 (overnight at $4^{\circ} \mathrm{C}$ ). HRP-labelled goat anti-rabbit antisera was applied at a dilution of 1:1000 for $2 \mathrm{~h}$ at room temperature and membranes were incubated in $0.5 \mathrm{mg} / \mathrm{mL}$ diaminobenzidine and $0.02 \% \mathrm{H}_{2} \mathrm{O}_{2}$ in TBS. The membranes were washed three times between each step with TBST (TBS with $2 \%$ Tween 20). 


\section{References}

Ablashi DV, Lapps W, Kaplan M, Whitman JE, Richert JR, Pearson GR (1998). Human herpesvirus-6 (HHV-6) infection in multiple sclerosis: A preliminary report. Mult Scler 4: 490-496.

Albright AV, Lavi E, Black JB, Goldberg S, O’Connor MJ, Gonzalezscaran o F (1998). The effect of human herpesvirus-6 (HHV-6) on cultured human neural cells-Oligodendrocytes and microglia. J NeuroVirol 4: 486-494.

Allen IV (1981). The pathology of multiple sclerosis-Fact, fiction and hypothesis. Neuropathol Appl Neurobiol 7: 169-172.

Allen IV, Brankin B (1993). Pathogenesis of multiple sclerosis-The immune diathesis and the role of viruses. J Neuropathol Exp Neurol 52: 95-105.

Bergstrom T (1999). Herpesviruses-A rationale for antiviral treatment in multiple sclerosis. Antiviral Res 41: $1-19$.

Berti R, Jacobson S (1999). Role of viral infection in the aetiology of multiple sclerosis-Status of current knowledge and therapeutic implications. CNS Drugs 12: 1-7.

Brankin B, Osman M, Herlihy L, Hawkins SA, Cosby SL (1996). Failure to detect measles virus RNA, by reverse transcription-polymerase chain reaction, in peripheral blood leucocytes of patients with multiple sclerosis. Mult Scler 1: 204-206.

Buckle GJ, Godec MS, Rubi JU, Tornatore CEO, Gajdusek DC, Asher DM (1992). Lack of JC viral genome sequences in multiple sclerosis brain tissue by polymerase chain reaction. Ann Neurol 32: 829831.

Campadelli-Fiume G, Mirandola P, Menotti L (1999). Human herpesvirus 6: An emerging pathogen. Emerg Infect Dis 5: 353-366.

Cook RD (1979). Observations on focal demyelinating lesions in cat optic nerves. Neuropathol Appl Neurobiol 5: 395-404.

Cook RD, Flower RLP, Dutton NS (1986). Light and electron microscopical studies of the immunoperoxidase staining of multiple sclerosis plaques using antisera to a feline-derived agent and to galactocerebroside. Neuropathol Appl Neurobiol 12: 63-79.

Cook RD, Wilcox GE (1985). Primary demyelination in the central nervous system of cats. Neuropathol Appl Neurobiol 11: 361-367.

Cook SD, Rohowsky-Kochan C, Bansil S, Dowling PC (1995). Evidence for multiple sclerosis as an infectious disease. Acta Neurol Scand Suppl 161: 34-42.

Cosby SL, McQuaid S, Duffy N, Lyons C, Rima BK (1988). Characterization of a seal morbillivirus. Nature 336: 115-116.

Diallo A, Barrett T, Lefevre PC, Taylor WP (1987). Comparison of proteins induced in cells infected with rinderpest and peste des petits ruminants viruses. J Gen Virol 68: 2033-2038.

Enbom M, Wang FZ, Fredrikson S, Martin C, Dahl H, Linde A (1999). Similar humoral and cellular immunological reactivities to human herpesvirus 6 in patients with multiple sclerosis and controls. Clin Diag Lab Immunol 6: 545-549.

Ehrlich GD, Glaser JB, Bryz-Gornia V, Maese J, Waldmann TA, Poiesz BJ, Greenberg SJ (1991). Multiple sclerosis, retroviruses and PCR. Neurology 41: 335-343.
Field EJ, Cowshall S, Narang HK, Bell TM (1972). Viruses in multiple sclerosis? Lancet Aug 5:2(7771): 280-281.

Flower RLP (1988). The isolation and characterization of viral agents from the central nervous system of cats. $\mathrm{PhD}$ Thesis, School of Veterinary Studies, Murdoch University, Western Australia.

Fraser KB, Allen IV, Armstrong MA, Dermott SE, Haire M, Millar JHD, Shirodaria PV, Thorne HV (1982). Failure to detect replicating viruses in brain and other tissues from multiple sclerosis patients. Lancet May 22:1(8282): 1185-1186.

Godec MS, Asher DM, Murray RS, Shin ML, Greenham LW, Gibbs CJ, Gajdusek DC (1992). Absence of measles, mumps and rubella viral gemone sequences from multiple sclerosis brain tissue by polymerase chain reaction. Ann Neurol 32: 401-404.

Goswami KKA, Cameron KR, Russell WC, Lange LS, Mitchell DN (1984). Evidence for the persistence of paramyxoviruses in human bone marrows. J Gen Virol 65: 1881-1888.

Hauw JJ, Esourolle R (1977). Filamentous and multilamellated cytoplasmic inclusions in progressive multifocal leukoencephalopath y. Acta Neuropathol Berlin 37: 263265.

Hayano M, Sung JH, Mastri AR (1976). "Paramyxo-like” intranuclear inclusions occurring in the nervous system in diverse unrelated conditions. J Neuropathol Exp Neurol 35: $287-294$.

Johnson RT (1985). Viral aspects of multiple sclerosis. Handbook Clin Neurol 3: 319-336.

Kirk J, Hutchinson WM (1978). The fine structure of the CNS in multiple sclerosis. I. Interpretation of cytoplasmic papovavirus-like and paramyxovirus-like inclusions. Neuropathol Appl Neurobiol 4: 343-356.

Kirk J, Zhou A-L (1996). Viral infection at the blood-brain barrier in multiple sclerosis-An ultrastructural study of tissues from a UK regional brain bank. Mult Scler 1: 242-252.

Komurian-Pradel F, Paranhos-Baccala G, Bedin F, Ounanian-Paraz A, Sodoyer M, Ott C, Rajoharison A, Garcia E, Mallet F, Mandrand B, Perron H (1999). Molecular cloning and characterization of MSRVrelated sequences associated with retrovirus-like particles. Virology 260: 1-9.

Kuhlmann-Krieg S, Sommer I, Schachner M (1988). Ultrastructural features of cultured oligodendrocytes expressing stage-specific cell-surface antigens. Dev Brain Res 39: $269-280$.

Kurtzke JF (1993). Epidemiologic evidence for multiple sclerosis as an infection. Clin Microbiol Rev 6: 382-427.

Labourdette G, Roussel G, Ghandour MS, Nussbaum JL (1979). Cultures from rat brain hemispheres enriched in oligodendrocyte-like cells. Brain Res 179: 199.

McCarthy KD, DeVellis J (1980). Preparation of separate astroglial and oligodendroglial cell cultures from rat cerebral tissue. J Cell Biol 85: 890-902.

Mirra SS, Takei Y (1976). Ultrastructural identification of virus in human central nervous system disease. Prog Neuropathol 3: 69-88.

Mitchell DN, Porterfield JS, Micheletti R, Lange LS, Goswami KKA, Taylor P, Jacobs JP, Hockley DJ, Salsbury AJ (1978). Isolation of an infectious agent from bone marrows of patients with multiple sclerosis. Lancet Aug 19:2(8086): 387-391. 
Monteyne P, Bureau JF, Brahic M (1998). Viruses and multiple sclerosis. Cur Opin Neurol 11: 287-291.

Muller CF, Fatzer RS, Beck K, Vandevelde M, Zurbriggen A (1995). Studies on canine distemper virus persistence in the central nervous system. Acta Neuropathol 89: 438-445.

Narang HK, Field EJ (1973). Paramyxovirus-like tubules in multiple sclerosis biopsy material. Acta Neuropathol Berlin 25: 281-290.

Norrby E (1978). Virus antibodies in multiple sclerosis. Prog Med Virol 24: 1-39.

Pathak S, Webb HE (1976). Paramyxovirus-like inclusions in brain of patients with severe multiple sclerosis. Lancet Aug 7:2(7980): 311.

Perron H, Garson JA, Bedin F, Beseme F, Paranhosbaccal a G, Komurianpradel F, Mallet F, Tuke PW, Voisset C, Blond JL, Lalande B, Seigneurin JM, Mandrand B (1997). Molecular identification of a novel retrovirus repeatedly isolated from patients with multiple sclerosis. Proc Natl Acad Sci USA 94: 7583-7588.

Prasad I, Broome JD, Pertschuk LP, Gupta J, Cook AW (1977). Recovery of paramyxovirus from the jejunum of patients with multiple sclerosis. Lancet May 28:1(8022): 1117-1119.

Prineas J (1972). Paramyxovirus-like particles associated with acute demyelination in chronic relapsing multiple sclerosis. Science 178: 760-763.

Prineas J (1975). Pathology of the early lesion in multiple sclerosis. Hum Pathol 6: 531-554.

Raine CS, Schaumburg HH, Snyder DH, Suzuki K (1975). Intranuclear 'paramyxoviruslike' material in multiple sclerosis, adreno-leukodystrophy and Kuf's disease. J Neurol Sci 25: 29-41.

Reddy EP, Sandberg-Wolheim M, Mettus RW, Ray PE, DeFreitas E, Kowprowski H (1989). Amplification and molecular cloning of HTLV-I sequences from DNA of multiple sclerosis patients. Science 243: 529533.

Rodriguez M, Scheithauer B (1994). Ultrastructure of multiple sclerosis. Ultrastruc Pathol 18: 3-13.

Rosenbergova M, Pristasova S (1991). Relationship of $2^{\prime}, 3^{\prime}$ cyclic nucleotide $3^{\prime}$-phosphohydrolase activity of large enveloped RNA viruses to host cell activity. Acta Virol 35: 401-407.

Sourberbielle BE, Szawlowski PWS, Russell WC (1995). Is there a case for a virus aetiology in multiple sclerosis? Scot Med J 40: 55-62.

Svenningsson A (1992). No evidence for spumavirus or oncovirus infection in relapsing-remitting multiple sclerosis. Ann Neurol 32: 711-714.

Tanaka R, Iwasaki Y, Koprowski H (1974). Unusual intranuclear filaments in multiple sclerosis brain. Lancet June 15:1(7868): 1236-1237.

Tanaka R, Iwasaki Y, Koprowski H (1975). Paramyxoviruslike structures in brains of multiple sclerosis patients. Arch Neurol 32: 80-83.

ter Meulen V, Koprowski H, Iwasaki I, Kackell YM, Muller D (1972). Fusion of cultured multiple sclerosis brain cells with indicator cells: Presence of nucleocapsids and virions and isolation of parainfluenza-type virus. Lancet July 1:2(7766): 1-5.

ter Meulen V, Stephenson JR (1983). The possible role of viral infections in multiple sclerosis and other related demyelinating diseases. In Multiple sclerosis. Pathology, diagnosis and management. Hallpike JF, Adams CWM, Tourtellotte WW (eds). London: Chapman and Hall, pp 241-274.

Wilcox GE, Flower RLP, Cook RD (1984). Recovery of viral agents from the central nervous system of cats. Vet Microbiol 9: 355-366. 